\title{
Effect of Reinforcement Clustering on Crack Initiation Mechanism in a Cast Hybrid Metal Matrix Composite during Low Cycle Fatigue
}

\author{
A. K. M. Asif Iqbal, Yoshio Arai*, Wakako Araki \\ Graduate School of Science and Engineering, Saitama University, Saitama, Japan. \\ Email: ${ }^{*}$ yarai@mech.saitama-u.ac.jp \\ Received July $3^{\text {rd }}, 2013$; revised August $3^{\text {rd }}, 2013$; accepted August $13^{\text {th }}, 2013$ \\ Copyright (C) 2013 A. K. M. Asif Iqbal et al. This is an open access article distributed under the Creative Commons Attribution \\ License, which permits unrestricted use, distribution, and reproduction in any medium, provided the original work is properly \\ cited.
}

\begin{abstract}
The reinforcement distribution of metal matrix composites (MMCs) plays an important role in low cycle fatigue. Thus, it is essential to study the effect of reinforcement clustering on the crack initiation mechanism of MMCs. In this study, the effect of reinforcement clustering on the microcrack initiation mechanism in a cast hybrid MMC reinforced with $\mathrm{SiC}$ particles and $\mathrm{Al}_{2} \mathrm{O}_{3}$ whiskers was investigated experimentally and numerically. Experimental results showed that microcracks always initiated in the particle-matrix interface, located in the cluster of the reinforcements. The interface debonding occurred in the fracture which created additional secondary microcracks due to continued fatigue cycling. The microcrack coalesced with other nearby microcracks caused the final fracture. To validate the experimental results on the microcrack initiation, three dimensional unit cell models using finite element method (FEM) were developed. The stress distribution in both the reinforcement clustering and non-clustering regions was analyzed. The numerical analysis showed that high stresses were developed on the reinforcements located in the clustering region and stress concentration occurred on the particle-matrix interface. The high volume fraction reinforced hybrid clustering region experienced greater stresses than that of the $\mathrm{SiC}$ particulate reinforced clustering region and low volume fraction reinforced hybrid clustering region. Besides, the stresses developed on the non-clustering region with particle-whisker series orientation were reasonably higher than that of the non-clustering region with particle-whisker parallel orientation. The high volume fraction reinforced hybrid clustering region is found to be highly vulnerable to initiate crack in cast hybrid MMC during low cycle fatigue.
\end{abstract}

Keywords: Cast Metal Matrix Composites; Crack Initiation; Reinforcement Clustering; Low Cycle Fatigue

\section{Introduction}

The metal matrix composites (MMCs) provide a combination of the metallic properties of the matrix (high toughness) with the ceramic properties of the reinforcement (high strength and high modulus) to give a material greater strength and stiffness, higher temperature capabilities and more excellent wear resistance than a similar monolithic material [1-5]. Therefore, MMCs are particularly attractive for structural applications such as aerospace and automotive industries and wear applications, especially in the frictional area of braking system [1]. The production techniques of MMCs have been well advanced in recent years, such as powder metallurgy, the extrusion process and liquid infiltration. However in

${ }^{*}$ Corresponding author. practice, it is often difficult to obtain a homogeneous distribution of reinforced particles or whiskers. Further, it has been found that the non-uniformity in the reinforcement arrangement can have significant effects on the mechanical properties of the MMCs [6,7]. Existing experimental and theoretical evidences suggest that the homogeneity of particles or whiskers spatial arrangement plays a key role in controlling the yield strength, ductility, fatigue and fracture behaviors of MMCs [8]. It is generally agreed that the yield strength and the work hardening increase with increased clustering of reinforcements [9]. However, the failure strain is significantly reduced in a clustered microstructure [10]. This is often attributed to the stress concentration in the reinforcement clusters [11], which may lead to preferential nucleation and propaga- 
tion of damage in the clusters. Davidson [12] has experimentally observed crack initiation in particle clusters in the AA2014 + 15\% $\mathrm{SiC}_{\mathrm{p}} \mathrm{MMC}$, and reported that the preferential site for crack propagation is the regions of higher particle volume fractions. In addition, Boyd et al. [13] observed that damage develops in the particlerich zones in $\mathrm{SiC}_{\mathrm{p}}$ reinforced $\mathrm{Al}$ alloy. This damage was caused by particle rupture with interfacial decohesion. They also observed that on the fracture surface of tested specimens, the particle density was higher than the material mean value. Bourgeois et al. [14] showed experimentally on an $\mathrm{Al}-\mathrm{SiC}$ composite that damage grows first in the whole composite but localization occurs in a particle-rich zone. Besides, Prangnell et al. [15] studied compression of an $\mathrm{Al}-\mathrm{Si} / \mathrm{SiC}_{\mathrm{p}} \mathrm{MMC}$. They observed that the porosity increases more in the clustered zone than in the matrix zone, and particle cracking is the less dominant fracture mode in the clustered region than in the other region. Murphy and Clyne [16] pointed out in the case of as-cast $\mathrm{Al}-\mathrm{Si} / \mathrm{SiC}_{\mathrm{p}}$ composite, the preferential occurrence of porosity growth and particle rupture in clustered region. Furthermore, Yoshimura et al. [17] found that particle clustering decreases composite ductility and ultimate strength. Numerical simulation has also been done by many researchers which allowed the study of clustering more intensively. Li et al. [18] showed experimentally and verified by simulation on an $\mathrm{Al} / \mathrm{SiC}_{\mathrm{p}}$ composite that rupture localizes preferentially in particle-rich regions. Moreover, Tszeng [19] modeled MMC in order to point out the influence of some cluster characteristics. This simulation showed that the load at which crack nucleation occurs is lower in the cluster than outside. At present, numbers of researchers have employed the numerical analysis to predict the effects of reinforcements on the MMCs. By and large, these analyses approached the problem by considering the unit cell model, where one particle or whisker was embedded in matrix $[20,21]$. In addition, the shape of the particle or whisker was assumed to be cylindrical, spherical, rectangular or cubical [22,23]. Zhang et al. [24] have analyzed the effect of particle clustering on the flow behaviour of $\mathrm{SiC}$ particulate reinforced Al-MMC by using the microstructure based cell model. They successfully predicted the flow behaviour and revealed that the percentage of the particle cracking in the particle clustering model is higher compared with that in the particle random distribution model.

These results concerning the damage initiation and fracture weigh in favor of either particulate- or whisker-reinforced MMCs. The experimental and numerical analysis for hybrid MMC is rare. At present, studies of cast hybrid MMCs are limited in the investigation of fracture mechanisms and wear properties [25]. Besides, the au- thors of this article have previously investigated the microcrack initiation and stage by stage growth of the crack to final failure in cast hybrid MMC [26]. They experimentally investigated the hybrid effect on the crack initiation mechanism. However, the effect of reinforcement clustering on the initiation of microcracks in hybrid MMC is very complicated due to the presence of particles and whiskers together. Due to the complicated microstructure, various experimental and numerical investigations are needed to be explained to clarify the damage nucleation and fracture mechanism of the composite. Thus, in the present work, the effect of reinforcement clustering on the crack initiation mechanism in cast hybrid $\mathrm{MMC}$ reinforced with $\mathrm{SiC}$ particles and $\mathrm{Al}_{2} \mathrm{O}_{3}$ whiskers was investigated. Fractographic analysis was used to explain the clustering dependency in microcrack nucleation. A three-dimensional unit-cell model in the periodic boundary condition was developed using finite element method (FEM) to analyze the stress distribution in the clustering and non-clustering regions which could lead to microcrack initiation in cast hybrid MMC.

\section{Materials and Experimental Procedures}

The cast hybrid metal matrix composite was fabricated with $21 \mathrm{vol} \% \mathrm{SiC}$ particles and $9 \mathrm{vol} \% \mathrm{Al}_{2} \mathrm{O}_{3}$ whiskers as reinforcements and the aluminium alloy JIS-AC4CH as matrix [27]. The material was fabricated by the squeeze casting process with a $100 \mathrm{MPa}$ maximum pressure, using a hybrid preform made of $\mathrm{SiC}$ particles and $\mathrm{Al}_{2} \mathrm{O}_{3}$ whiskers. The squeeze casting pressure of $100 \mathrm{MPa}$ was adequate to overcome the resistance against flow and to press the melt into all the open pores of the hybrid preform. The materials were heat treated using the $\mathrm{T} 7$ process. The chemical composition of $\mathrm{AC} 4 \mathrm{CH}$ alloy is listed in Table 1. As described in the previous report [26], due to the formation process of the preform the whiskers in the hybrid MMC are randomly oriented in a plane. "Longitudinal cross section" is defined as the plane and "lateral cross section" is defined as the one perpendicular to the plane in this article.

Figure 1 shows the lateral and longitudinal microstructures of the hybrid MMC. Most of the SiC particles in the hybrid MMC were rectangular with sharp corners (Figures 1(a) and (b)), and most of the $\mathrm{Al}_{2} \mathrm{O}_{3}$ whiskers were roller-shaped (Figures 1(a) and (b)). The average length of $\mathrm{SiC}$ particles and the $\mathrm{Al}_{2} \mathrm{O}_{3}$ whiskers was 23 $\mu \mathrm{m}$ and $35 \mu \mathrm{m}$ respectively. The average diameter of the $\mathrm{Al}_{2} \mathrm{O}_{3}$ whiskers was $2 \mu \mathrm{m}$. The $\mathrm{Al}_{2} \mathrm{O}_{3}$ whiskers were randomly oriented in the same plane as the longitudinal cross section of the specimen. At frequent intervals, clusters of $\mathrm{SiC}$ particles and $\mathrm{Al}_{2} \mathrm{O}_{3}$ whiskers were observed in the hybrid MMC as indicated by the broken lines in Figures 
Table 1. Chemical composition of AC4CH alloy, (wt\%).

\begin{tabular}{ccccc}
\hline $\mathrm{Si}$ & $\mathrm{Fe}$ & $\mathrm{Mg}$ & $\mathrm{Ti}$ & $\mathrm{Al}$ \\
\hline 7.99 & $0.2(\max )$ & 0.57 & 0.07 & $\mathrm{Bal}$ \\
\hline
\end{tabular}

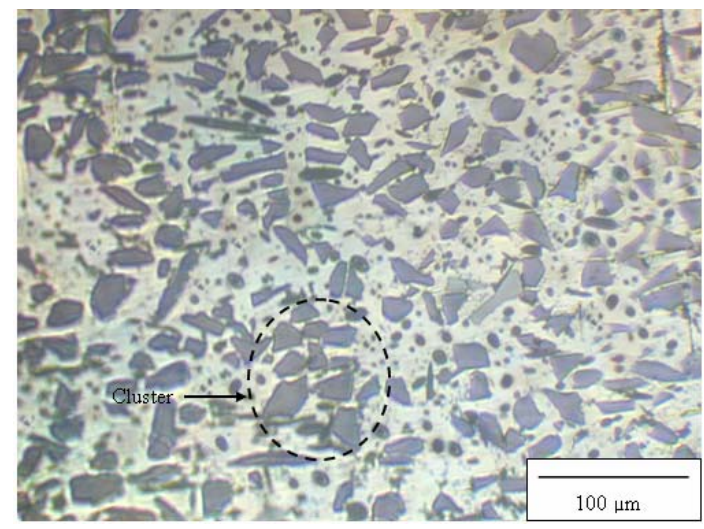

(a)

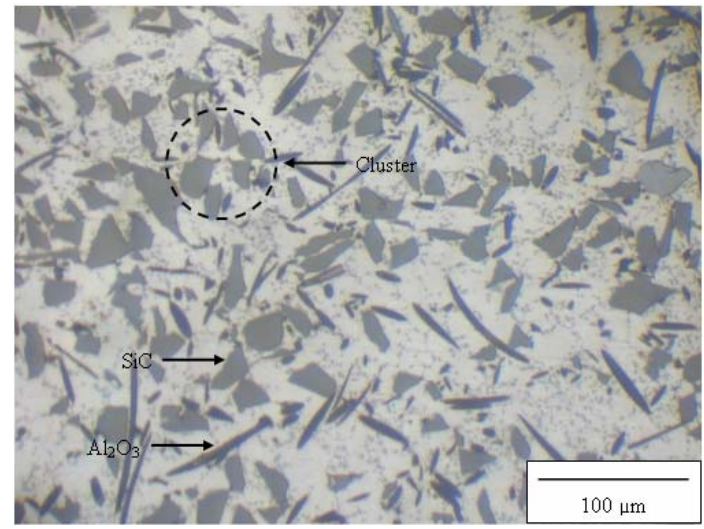

(b)

Figure 1. Microstructure in (a) lateral and (b) longitudinal cross section of hybrid MMC showing cluster of reinforcements.

1(a) and (b), respectively. The local volume fraction of the reinforcement in the clustering region is found to be $60 \%$. The mechanical properties of reinforcement materials and hybrid MMC are shown in Table 2. The listed properties for the hybrid MMC are along the direction in the longitudinal cross section. Conventional three point bending tests were carried out on rectangular bar smooth specimens to reduce the observation area of crack initiation. The specimen dimensions were as follows: length of $100 \mathrm{~mm}$, thickness of $6 \mathrm{~mm}$ and width of $8 \mathrm{~mm}$. The machined surfaces of the specimens were polished by using a polishing machine with 15,3 , and $1 \mu \mathrm{m}$ diamond particles sequentially until all scratches and surface machining marks were removed. Three point bending tests were performed using special bending fixtures equipped with a $5 \mathrm{kN}$ load cell in a Shimazu Servo Pulser. The span distance was $60 \mathrm{~mm}$. Load and deflection data were re-
Table 2. Mechanical properties of reinforcement and tested materials.

\begin{tabular}{ccccc}
\hline Parameters & $\mathrm{Al}_{2} \mathrm{O}_{3}$ & $\mathrm{SiC}$ & $\begin{array}{c}\mathrm{Al} \text { alloy } \\
\mathrm{AC} 4 \mathrm{CH}\end{array}$ & $\begin{array}{c}\text { Hybrid } \\
\mathrm{MMC}\end{array}$ \\
\hline Young's modulus (GPa) & 380 & 450 & 70.0 & 142 \\
Poisson's ratio & 0.27 & 0.20 & 0.33 & 0.28 \\
Yield strength (MPa) & - & - & 131 & 166 \\
Tensile strength (MPa) & - & - & 262 & 228 \\
Tensile elongation (\%) & & & 9.22 & 2.77 \\
\hline
\end{tabular}

corded by a computer data acquisition system. First, the Monotonic bending tests were conducted at a displacement rate of $0.0025 \mathrm{~mm} \cdot \mathrm{s}^{-1}$. The strength of the hybrid MMC was calculated from the maximum load at failure as a nominal bend stress $\sigma_{c}=386 \mathrm{MPa}$. Cyclic fatigue tests were conducted in the load control mode under the load ratio $R=0.1$ at the frequency of $0.5 \mathrm{~Hz}$. Three specimens of hybrid MMC which are mentioned in this article TP-1, TP-2 and TP-3 were tested with the maximum stresses of $0.7 \sigma_{c}, 0.8 \sigma_{c}$, and $0.9 \sigma_{c}$. All tests were carried out at room temperature. The number of cycles to failure was considered as the fatigue life $N_{f}$. To observe the initiation and growth of microcracks, the plastic replica technique was used at various times during the fatigue life. During replication, the specimen was held at mean load to ensure that any cracks that might be present would be fully opened. Replicas were taken using Bioden replicating films softened in acetone. Finally, an optical microscope was used to examine the replicas. Prior to testing, no cracks were seen. In this article, "crack initiation" is defined as the point at which a black line of several micrometers is first observed in the magnified replica image, during the cyclic loading test. The tensile and fracture surfaces were comprehensively examined using scanning electron microscopy (SEM) and energy-dispersive $\mathrm{x}$-ray spectroscopy (EDS) to characterize the crack initiation site.

\section{Experimental Results}

The initiation and early propagation of the microcracks on the smooth surface of the hybrid MMC are observed from optical micrographs of the same areas on replicas during fatigue testing. Figure 2 shows the optical micrographs of replicas obtained at various stages of fatigue testing of the hybrid MMC specimen TP-2. For TP-2, at $14 \%$ of the fatigue life, several cracks of length around $10-15 \mu \mathrm{m}$ were initiated (indicated by arrows in Figure 2(a)). These cracks then coalesced together, and at $26 \%$ of the fatigue life, the crack extended to $160 \mu \mathrm{m}$ in length (Figure 2(b)). A few cracks $15-25 \mu \mathrm{m}$ in length were formed ahead of the main crack tip at $60 \%$ of the fatigue 
life, (arrows in Figure 2(c)). At 90\% of the fatigue life, all of these cracks coalesced and a fatal crack was produced (Figure 2(d)). The size of the fatal crack was around $500 \mu \mathrm{m}$ on the specimen surface. The final failure took place at 2110 cycles. Similar phenomena were observed in the specimen TP- 1 and TP-3. Figure 3 shows the optical micrograph of the crack initiation site at the matching tensile surface of the fractured specimen TP-2. It is apparent that the microcracks initiated at the particle-matrix interface (as indicated by the "Particle" 1 " and the "Matrix" ${ }_{1}$ "arrows on the left in Figure 3 which correspond to the microcracks in Figure 2(a)). The crack initiated $\mathrm{SiC}$ particle was located in the cluster of $\mathrm{SiC}$ particles and $\mathrm{Al}_{2} \mathrm{O}_{3}$ whiskers (as indicated by the circles "cluster-1" in Figure 3). Moreover, another two SiC particles were found located in parallel and in series to the crack initiated $\mathrm{SiC}$ particle in the clustering region (As indicated by the "Particle ${ }_{2}$ " and "Particle" arrows respectively in Figure 3). Furthermore, one $\mathrm{Al}_{2} \mathrm{O}_{3}$ whisker was found located parallel and another one located in series (as indicated by the "Whisker," and "Whisker," arrows respectively in Figure 3) very close to the crack initiated $\mathrm{SiC}$ particle. The cluster-2 region of Figure 3 indicates the secondary microcrack initiation site. It is also observed that the secondary microcracks were initiated at the particle-matrix interface which was located in the cluster of $\mathrm{SiC}$ particles and $\mathrm{Al}_{2} \mathrm{O}_{3}$ whiskers (as indicated by the "Particle" and the "Matrix ${ }_{2}$ " arrows in Figure 3, which correspond to the microcracks in Figure 2(c)). Figure 4 shows the SEM image of the matching fracture surfaces of the microcrack initiation site at the cluster of $\mathrm{SiC}$ particles and $\mathrm{Al}_{2} \mathrm{O}_{3}$ whiskers in the hybrid MMC specimen TP-2. The cluster region is indicated by the circle "cluster-1" in Figure 4(a) which is corresponding to the "cluster-1" in Figure 3 where the inner particle clustering is shown in Figure 4. The dark flat area indicated by $P_{1}$ in Figure 4(a) corresponds to the location indicated by the "Particle" arrow in Figure 3, and the area $M_{1}$ in Figure 4(a) corresponds to the location indicated by the "Matrix," arrow in Figure 3. Figure 4(b) shows the EDS mapping analysis results on the areas corresponding to Figure 4(a). The presence of $\mathrm{Al}$, $\mathrm{Si}$, and $\mathrm{O}$ on the fracture surfaces is indicated by the green, blue, and red colors respectively in Figure 4(b). The blue area indicated by $P_{1}$ in Figure 4(b) contains a significant amount of $\mathrm{Si}(94 \%)$ and a small amount of $\mathrm{Al}$ $(6 \%)$, identifying the area as a $\mathrm{SiC}$ particle (corresponding to $P_{1}$ in Figure 4(a)). The green area indicated by $M_{1}$ contains a large amount of $\mathrm{Al}(92 \%)$ and a small amount of $\mathrm{Si}(8 \%)$, indicating that this area is Al matrix (corresponding to $M_{1}$ in Figure 4(a)). Therefore, the blue and green area indicated by the $P_{1}-M_{1}$ pair in the matching halves denoted the crack initiation site in the cluster of
$\mathrm{SiC}$ particles and $\mathrm{Al}_{2} \mathrm{O}_{3}$ whiskers (Figure 2(a)) where $\mathrm{SiC}$ particle-matrix interfacial debonding occurred. The

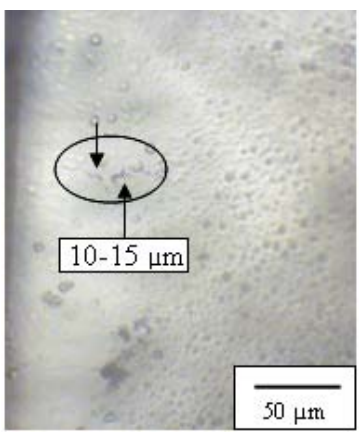

(a)

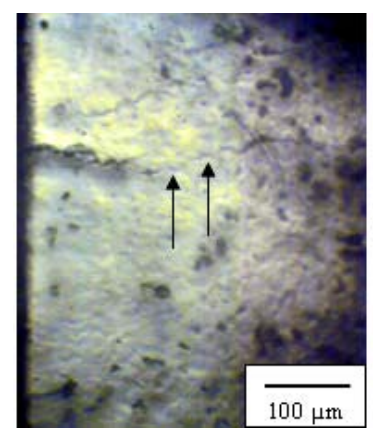

(c)

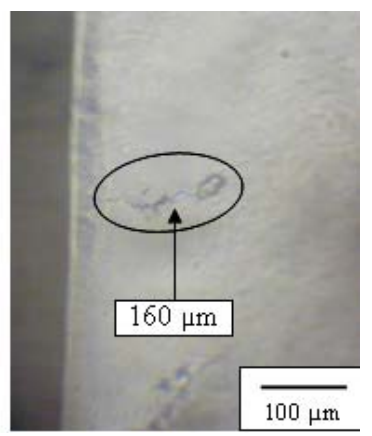

(b)

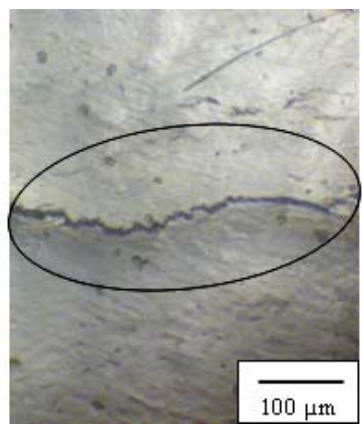

(d)
Figure 2. Crack initiation at the cluster of reinforcement and crack propagation at various stages of fatigue life of hybrid MMC specimen TP-2: $\sigma_{\max }=308 \mathrm{MPa}, N_{\mathrm{f}}=2110$ cycles. (a) $N_{1} / N_{f}=0.14$; (b) $N_{1} / N_{f}=0.26$; (c) $N_{1} / N_{f}=0.6$; (d) $\mathbf{N}_{1} / \mathbf{N}_{\mathrm{f}}=\mathbf{0 . 9}$.

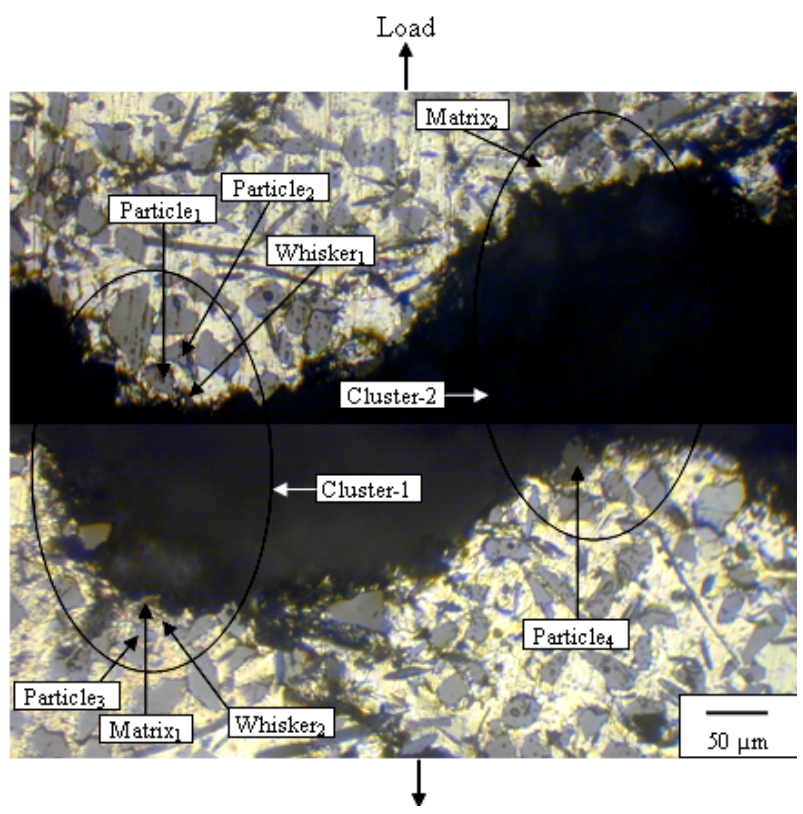

Figure 3. Optical micrograph of the crack initiation site at the matching tensile surface of the fractured specimen TP-2. 


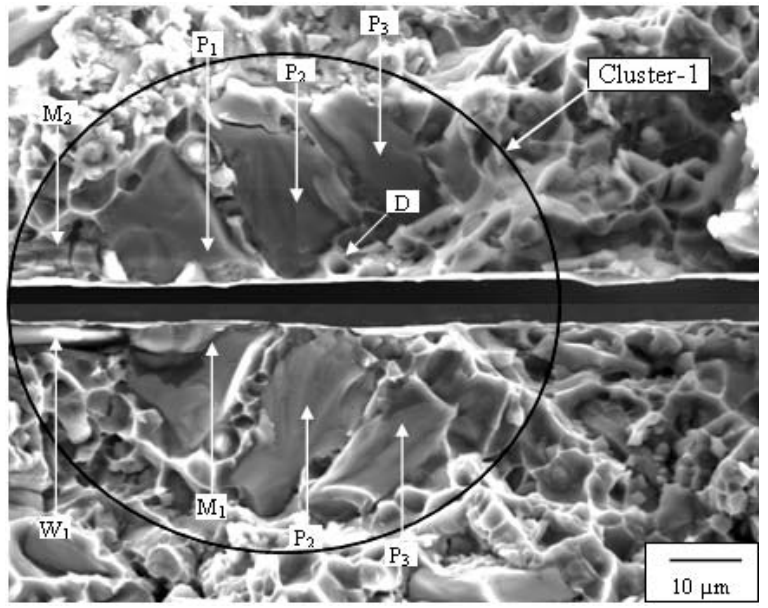

(a)

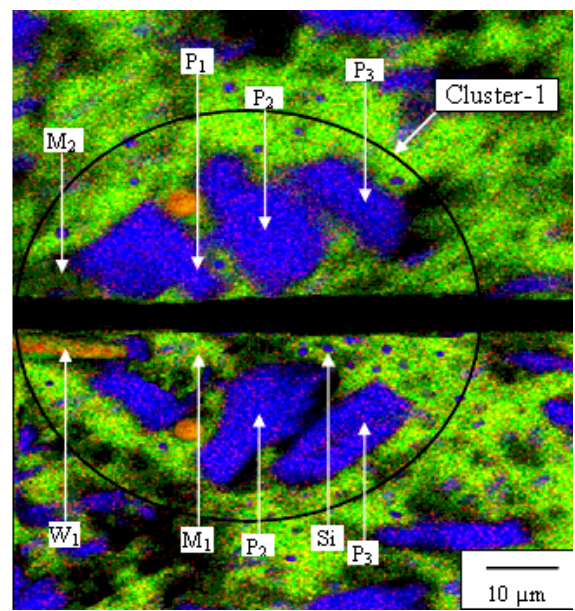

(b)

Figure 4. Matching fracture surface of microcrack initiation site in TP-2: (a) SEM micrograph (b) EDS mapping analysis.

blue $P_{2}-P_{2}$ and $P_{3}-P_{3}$ pair in Figure 4(b) indicated the presence of $\mathrm{SiC}$ particles on both sides of the fractured surface, meaning that interface debonding was followed by transgranular fracture in this clustering region (corresponding to the $P_{2}-P_{2}$ and $P_{3}-P_{3}$ pair in Figure 4(a)). The coexistence of green and red, indicating the presence of both $\mathrm{Al}$ and $\mathrm{O}$, identifies this area as an $\mathrm{Al}_{2} \mathrm{O}_{3}$ whisker, denoted by $W_{1}$ in Figure 4(b) (corresponding to $W_{1}$ in Figure 4(a)). This $\mathrm{Al}_{2} \mathrm{O}_{3}$ whisker was located very close to the debonded $\mathrm{SiC}$ particle. Interfacial debonding was also found in this $\mathrm{Al}_{2} \mathrm{O}_{3}$ whisker, as indicated by the $W_{1}-M_{2}$ pair in Figure 4(b) (corresponding to the $W_{1}-M_{2}$ pair in Figure 4(a)). Between the $P_{1}-M_{1}$ pair and the neighboring $\mathrm{SiC}$ particle on the specimen surface in Figure 4(a), a number of dimples were nucleated (indicated by the $D$ arrow in Figure 4(a)) in the aluminum alloy matrix. EDS mapping analysis confirmed the presence of a few Si particles on the opposite side of the dimples (as indicated by the Si arrow in Figure 4(b)). Dimple formation indicated the occurrence of void nucleation, which was induced by plastic deformation of the Al matrix at the second phase Si particles. However, the edge of the dimples was not as clear as those in the unstable fracture region are, likely due to the mutual contact effect due to cyclic loading. Similar observations were made for the fracture surface of the specimens TP-1 and TP-3. The above observations clearly demonstrated the effect of reinforcement cluster on microcrack initiation mechanism in hybrid MMC. Microcracks were always initiated at the particle-matrix interfaces where an $\mathrm{Al}_{2} \mathrm{O}_{3}$ whisker was also located very near to the crack initiated SiC particle (marked by $W_{1}$ in Figure 4). Previous researches reported that the main reason of microcrack initiation in the particulate or whisker reinforced system is debonding at the reinforcement-matrix interface $[6,28,29]$. The results obtained for hybrid MMC are consistent with these observations. Moreover, the results showed that the crack initiated particles always existed in the cluster of reinforcement, indicating the vulnerability of the clustering region in microcrack initiation.

Figure 5 illustrates the surface view and the cross sectional view for describing the crack initiation mechanism in the cluster of the hybrid MMC. It appears that the crack initiation sites of hybrid MMC is at the interface of the particle-matrix which is located in the cluster of the reinforcement. This clustering effect might be occurred due to the elastic-plastic interaction between the reinforcing particles, whisker and matrix. Furthermore, the local volume fraction of the reinforcements in the clustering region is found reasonably higher than that of the non-clustering region which could lead to initiate microcracks in the reinforcement clustering region. Besides, few $\mathrm{SiC}$ particles and $\mathrm{Al}_{2} \mathrm{O}_{3}$ whiskers were found located in parallel and series orientation to the crack initiated $\mathrm{SiC}$ particle which might affect the crack initiation mechanism of hybrid MMC. Therefore, to understand the characteristics of the elastic-plastic stress fields, a numerical analysis is carried out on the reinforcing particles, whisk-

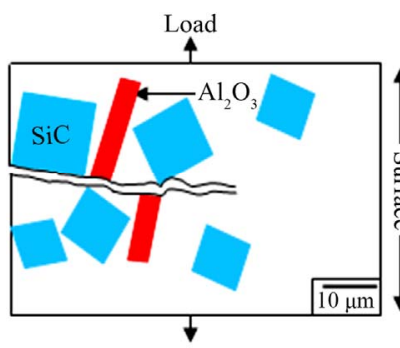

(a)

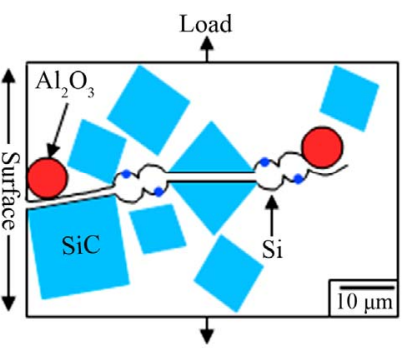

(b)
Figure 5. Schematic diagram of fatigue crack initiation mechanism at the cluster of reinforcement in hybrid MMC (a) surface view (b) cross sectional view. 
ers and matrix in the clustering and non-clustering regions as described in the following section.

\section{Numerical Model}

To characterize the effect of reinforcement clustering on stress distribution in hybrid MMC (reinforced by $\mathrm{SiC}$ particles and $\mathrm{Al}_{2} \mathrm{O}_{3}$ whiskers), three dimensional (3-D) unit cell models using finite element method (FEM) were developed. ABAQUS software [30] was used for the calculation. The models consist of $\mathrm{SiC}$ particle, $\mathrm{Al}_{2} \mathrm{O}_{3}$ whisker and $\mathrm{Al}$ alloy matrix. The schematic illustrations and finite element mesh of the models are shown in Figures 6-8. Figure 6 represents the reinforcement clustering region of hybrid $\mathrm{MMC}$ with three different $\mathrm{SiC}$ particle and $\mathrm{Al}_{2} \mathrm{O}_{3}$ whisker arrangement. In model-1 (Figure 6(c)), $\mathrm{SiC}$ particulate reinforced clustering region is shown. In Model-2 and 3 (Figures 6(d) and (e)), particles are located around a whisker, showing the clustering of both the $\mathrm{SiC}$ particles and $\mathrm{Al}_{2} \mathrm{O}_{3}$ whisker, representing the hybrid clustering regions. Whereas, Model- 4 and 5 (Figures 7 and 8) includes a particle and a whisker which are located in series and parallel orientation to each other, representing the non-clustering region of hybrid MMC. In this numerical analysis, it is assumed that all the $\mathrm{SiC}$ particles other than the center particles in Model-1 are cubic shape of length $b$ and the whiskers are rectangular shape of length $l$ and width $d$ respectively. However, the center $\mathrm{SiC}$ particles of model-1 (Figure 6(c)) are considered as the rectangular shape of length $a$, width $w$ and height $h$. Only $1 / 8$ of one unit cell is treated because of the symmetry of the cell. For models-3, 4 and 5 , reinforcement volume fractions is modeled as real microstructure of hybrid $\mathrm{MMC}$ of $9 \mathrm{vol} \% \mathrm{Al}_{2} \mathrm{O}_{3}$ whisker and $21 \mathrm{vol} \% \mathrm{SiC}$ particles in an $\mathrm{Al}$ alloy matrix. On the other hand, the reinforcement volume fraction of model1 and model-2 is kept $58 \mathrm{vol} \%$ and $51 \mathrm{vol} \%$ respectively as the local volume fraction of the reinforcements usually increases in the clustering region as shown in Figure 1. Size determination of the model was made by the following formulae: $b^{3} / L H^{2}=V_{p}$ (for cubic shaped particles) and $l d^{2} / L H^{2}=V_{w}$ (for whisker), where, $V_{p}$ and $V_{w}$ is the particle and whisker volume fraction respectively. The $\mathrm{SiC}$ particles and $\mathrm{Al}_{2} \mathrm{O}_{3}$ whiskers were modeled as linear elastic. The behaviour of $\mathrm{Al}$ alloy matrix was modeled as isotropic elastic-plastic response. Symmetric boundary condition is applied to the $\mathrm{Y}-\mathrm{Z}$ plane at the left, $\mathrm{X}-\mathrm{Y}$ plane at the front and $X-Z$ plane at the top of the models. Moreover, periodic boundary condition is applied to the

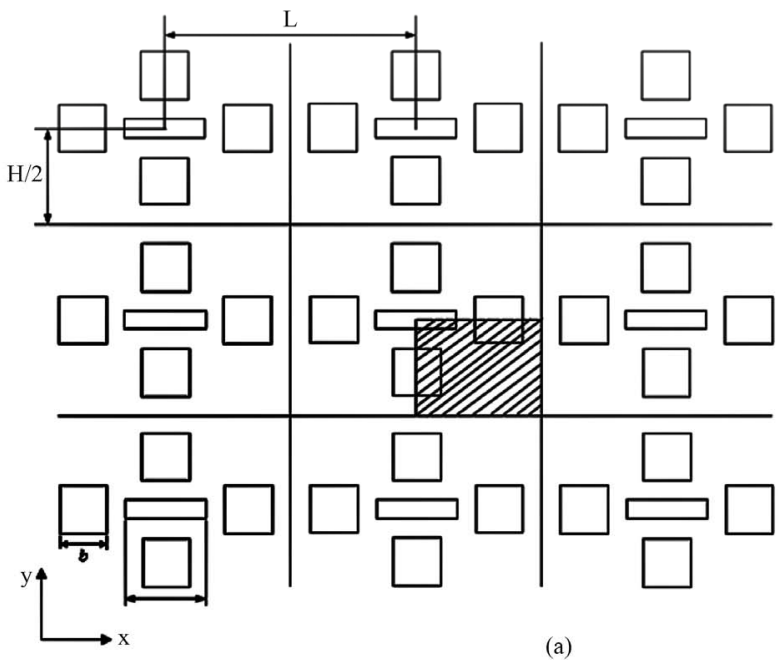

(a)

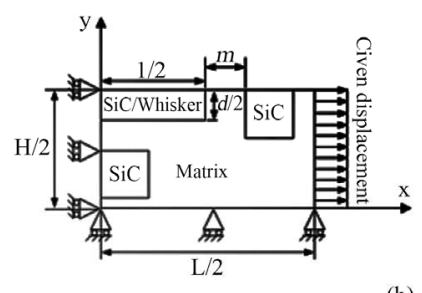

(b)
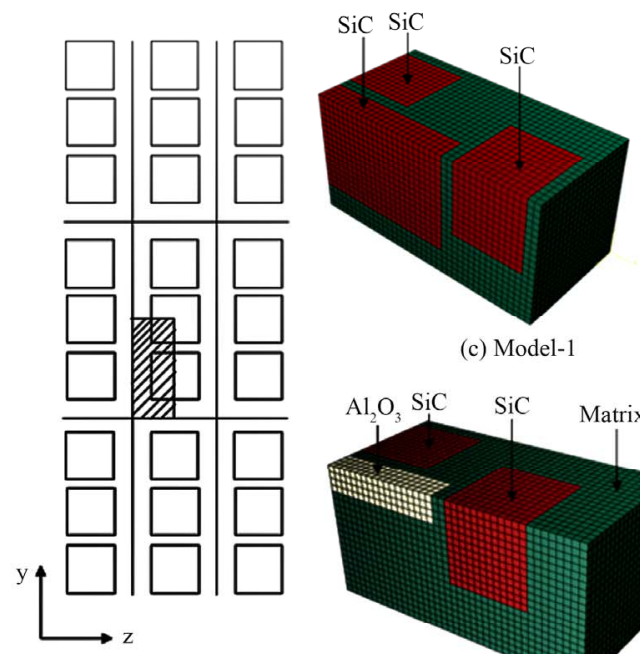

(c) Model-1

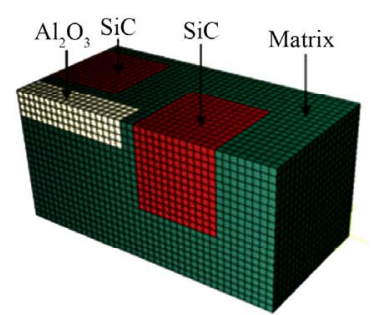

(d) Model-2

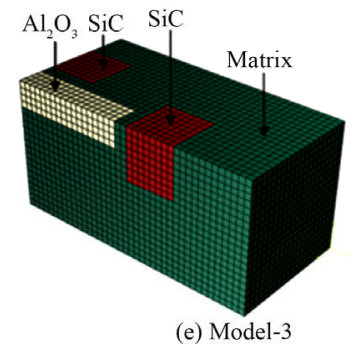

Figure 6. Schematic illustration of reinforcement clustering region of hybrid MMC: (a) periodic particle and whisker arrangement (b) 1/8 of one unit cell, analysis based on symmetry (c) finite element mesh of Model-1 (d) Model-2 (e) Model-3. 


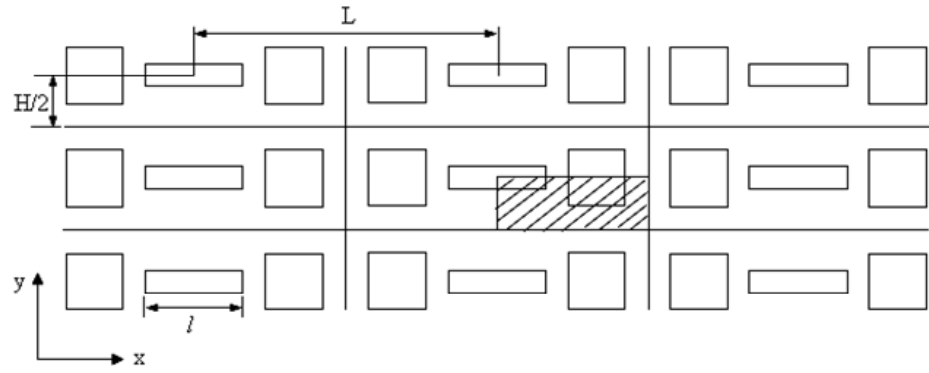

(a)

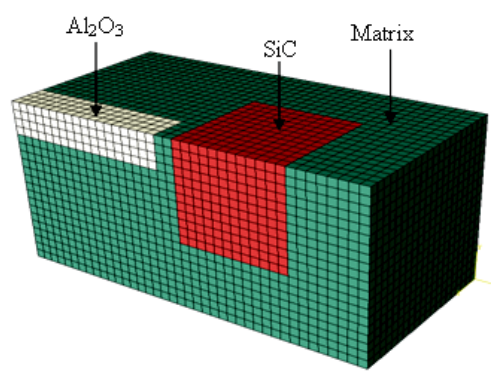

(b)

Figure 7. Model-4 representing the non-clustering region of hybrid MMC where particle and whisker is placed in series: (a) schematic illustration of the periodic particle and whisker arrangement (b) finite element mesh.

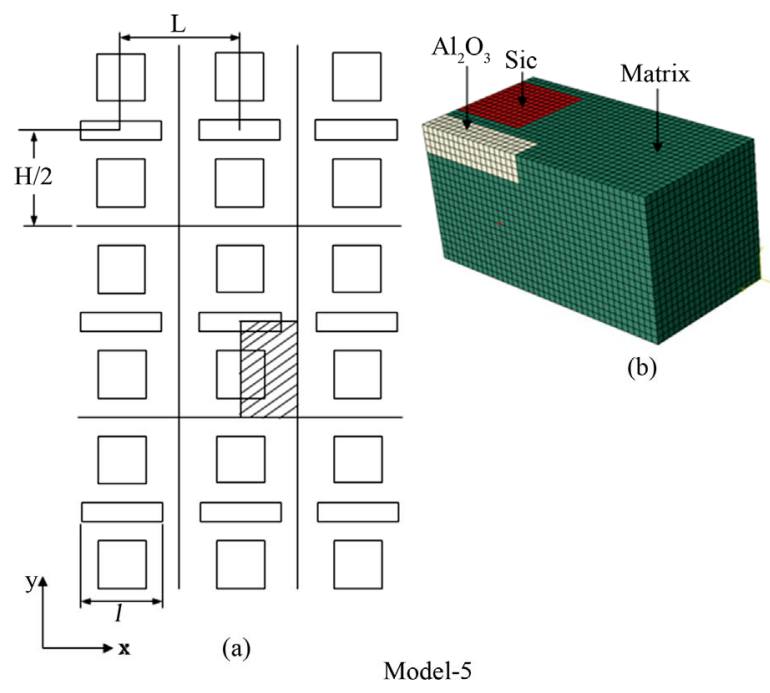

Figure 8. Model-5 representing the non-clustering region of hybrid MMC where particle and whisker is placed in parallel: (a) schematic illustration of the periodic particle and whisker arrangement (b) finite element mesh.

$\mathrm{X}-\mathrm{Z}$ plane at the bottom and X-Y plane at the back of all the models. A uniform displacement of $0.04 \mu \mathrm{m}$ for the half length of the unit cell, $20 \mu \mathrm{m}$ is applied to the $\mathrm{Y}-\mathrm{Z}$ plane at the right of all the models which is corresponding to a $308 \mathrm{MPa}$ nominal stress for the hybrid MMC.

\section{Numerical Results and Discussion}

In order to study the effects of reinforcement clustering on crack initiation mechanism, the stress distribution in hybrid MMC are highlighted in Figure 9. Figures 9(a), (b) and (c) represent normal stresses acting along the loading direction in the reinforcement clustering regions (Model-1, 2 and 3) whereas Figure 9(d) and e represent the normal stresses developed in the non-clustering regions (Model-4 and 5). It can be apparently found that the normal stresses developed in the reinforcement clustering regions (Figures 9(a), (b) and (c)) are significantly greater than that of the non-clustering regions (Figures 9(d) and (e)). It is noteworthy that the clustering regions reinforced with both $\mathrm{SiC}$ particles and $\mathrm{Al}_{2} \mathrm{O}_{3}$ whiskers, i.e. hybrid clustering region (Model-2 and 3, Figures 9(b) and (c)) experiences reasonably higher normal stresses than that of the clustering regions which is reinforced with only $\mathrm{SiC}$ particles (Model-1, Figure 9(a)), indicating the hybridization effect on the stress concentration and vulnerability of crack initiation in this region. Moreover, the hybrid clustering region with high volume fraction reinforcements (Model-2, Figure 9(b)) have greater stresses than that of the clustering region with low volume fraction reinforcement (Model-3, Figure 9(c)), indicating the influence of local volume fraction on the stress development in the clustering region of hybrid MMC. Besides, in all the models, the SiC particles-Al alloy interface edges experience higher stresses. This is attributed to the fact of the stress concentration in the vicinity of the reinforcement. Furthermore, the maximum stress concentration at the particle-matrix and whiskermatrix interface located in the clustering regions (Figures 9(b) and (c)) is much higher than that in the nonclustering regions (Figures 9(d) and (e)), suggesting the early interface debonding at the clustering regions and initiation of crack. In addition, it can be seen from Figures 9(b) and (c) that the stresses developed in the areas indicated by " $m$ " in Model-2 and Model-3 in Figure 6(b) are reasonably higher than the stresses developed in other sides of the clustering regions. This clearly indicates the hybrid effect of the hybrid MMC. The SiC particle and $\mathrm{Al}_{2} \mathrm{O}_{3}$ whisker deform elastically within the plastically deforming Al alloy matrix. Once the particle and whisker existed very close to one another, the elastic-plastic interaction occurs between these three materials, results the higher stress concentration at this location and cracks likely to initiate in this place. Therefore, the reinforcement clustering region where $\mathrm{SiC}$ particles and $\mathrm{Al}_{2} \mathrm{O}_{3}$ whisker exist very close to one another is highly vulnerable for crack initiation.

Figure 10 represents the variation of the maximum and minimum normal stresses developed on the interface of the reinforcement-matrix in all the models of both the 


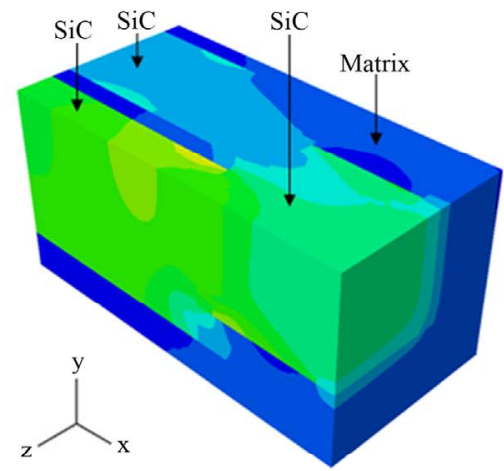

(a)

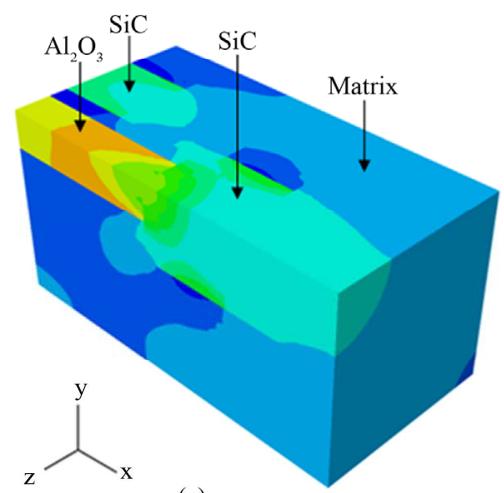

(c)

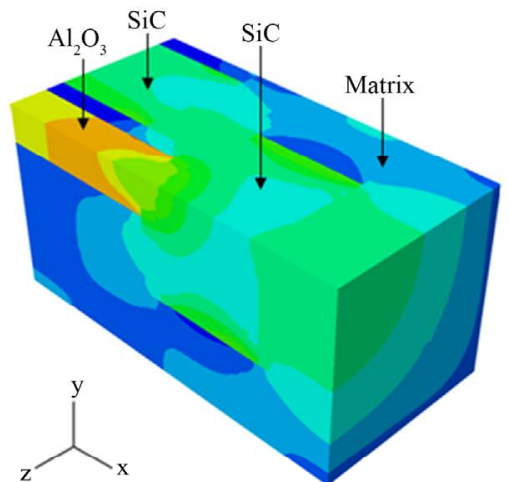

(b)

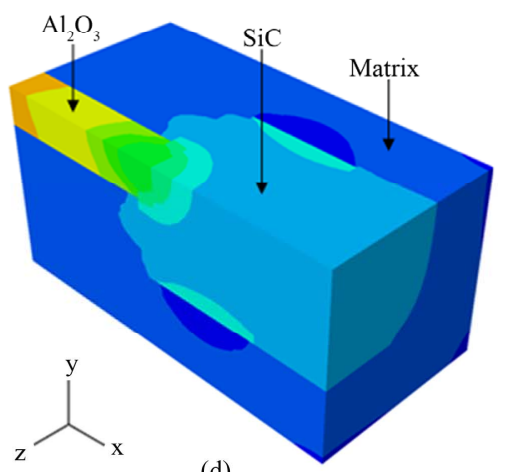

(d)
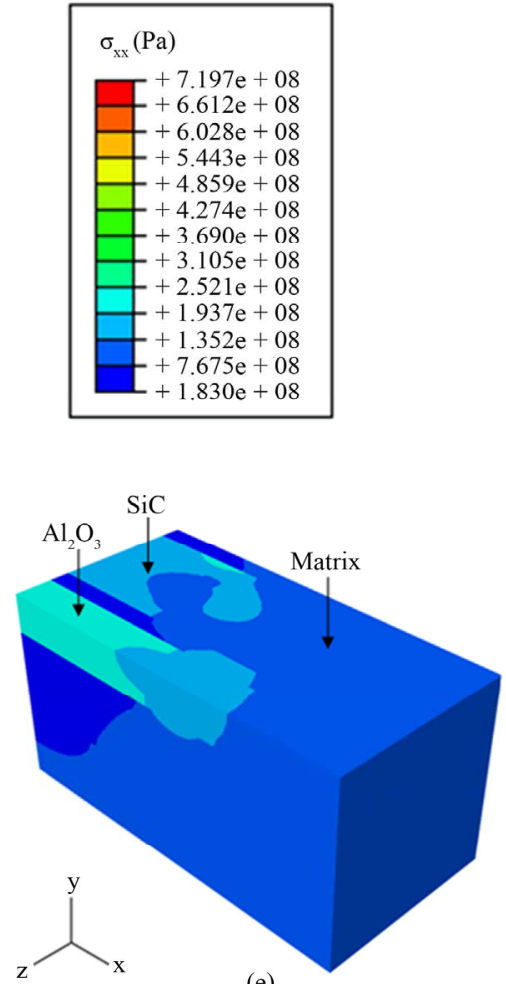

(e)

Figure 9. Numerical results normal stress along loading direction (a) in the SiC particulate reinforcement clustering region Model-1, (b) in the $\mathrm{SiC}$ particle and $\mathrm{Al}_{2} \mathrm{O}_{3}$ whisker reinforcement clustering region Model-2, (c) in the $\mathrm{SiC}$ particle and $\mathrm{Al}_{2} \mathrm{O}_{3}$ whisker reinforcement clustering region Model-3, (d) in the reinforcement non-clustering region Model-4 and (e) in the reinforcement non-clustering region Model-5.

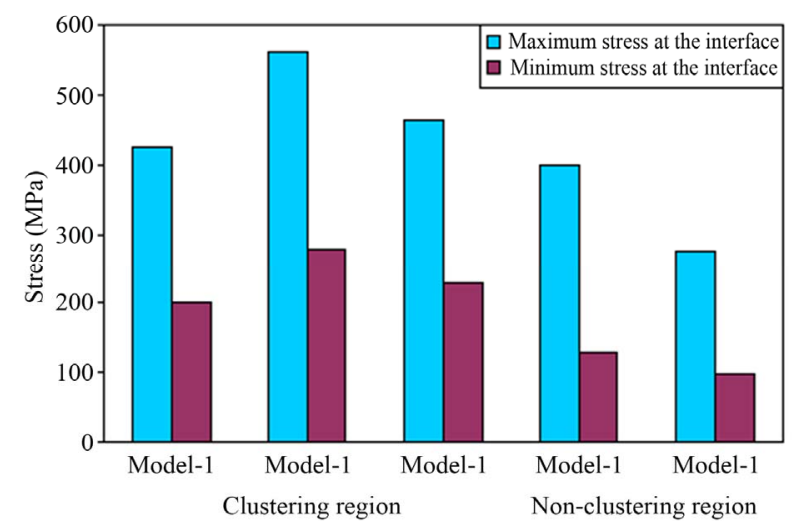

Figure 10. Comparison of the maximum and minimum normal stresses developed on the reinforcement-matrix interfaces in the clustering and non-clustering regions.

clustering and non-clustering regions. It is obvious from Figure 10 that the maximum and minimum normal stresses developed on the reinforcement-matrix interface in the clustering regions are extensively higher than that of the non-clustering regions. The normal stresses developed in the $\mathrm{SiC}$ particle and Al-matrix in the particulate clustering region (Model-1) is relatively lower than that of the hybrid clustering regions (Model-2 and Model-3). Moreover, from Figure 10, it is significant that the maximum normal stress on the particle-matrix interface in the reinforcement non-clustering region where $\mathrm{SiC}$ particle and $\mathrm{Al}_{2} \mathrm{O}_{3}$ whisker is placed in series (Model-4) are reasonably higher than those of the nonclustering region of Model-5, where $\mathrm{SiC}$ particle and $\mathrm{Al}_{2} \mathrm{O}_{3}$ whisker is placed in parallel orientation. Thus, it can be concluded that the reinforcements located in the clustering region experience higher stress than that of the non-clustering region and stress concentration at the interface of reinforcement-matrix is very high in the clustering region. In elastic state this clustering effect occurs because the ceramics have elastic stiffness one order higher than that of the Al alloy. In low cycle fatigue, elastic deformation occurred in the reinforcing $\mathrm{SiC}$ particles and $\mathrm{Al}_{2} \mathrm{O}_{3}$ whiskers whereas the matrix alloy deformed plastically during cyclic loading. As the reinforcements did not experience plastic deformation, the stress on the particle-matrix or whisker-matrix interfaces was higher in the hybrid MMC. In addition, the edge of the stiff ceramic reinforcements acted as stress concentrators that localizing the plastic strain between the parti- 
cles and the whiskers. Thus, a large strain mismatch occurred between these two reinforcement materials and the $\mathrm{Al}$ alloy. For this large strain mismatch, the stress became too high on the particle-matrix interface, and cracks initiated at these locations. Moreover, it can also be concluded that the stress concentration at the reinforcements has the dependency on the reinforcement volume fraction as well as at the reinforcement-matrix interface, indicating the vulnerability of the reinforcement cluster on fatigue crack initiation.

\section{Conclusions}

The effect of reinforcement clustering on crack initiation mechanism in cast hybrid MMC reinforced with $\mathrm{SiC}$ particles and $\mathrm{Al}_{2} \mathrm{O}_{3}$ whiskers was investigated experimentally and numerically. The following conclusions were made:

1) The experimental results showed that the crack initiated at the particle-matrix interface which was located in the cluster of the reinforcements in the cast hybrid MMC. The interface debonding occurred in the fracture which created additional secondary microcracks due to continued fatigue cycling. Numerous voids were formed ahead of the crack tip and the microcrack coalesced with other nearby microcracks;

2) The numerical analysis confirmed that the high stress was developed in the reinforcements located in the clustering region and stress concentration occurred on the particle-matrix interfaces. The stress concentration on the particle-matrix interface located in the high volume fraction reinforced hybrid clustering region is found to be very high compared to that in the $\mathrm{SiC}$ particulate reinforced clustering region and low volume fraction reinforced hybrid clustering region. Moreover, the non-clustering region where $\mathrm{SiC}$ particle and $\mathrm{Al}_{2} \mathrm{O}_{3}$ whisker located in series experienced higher stresses than that of the non-clustering region where $\mathrm{SiC}$ particle and $\mathrm{Al}_{2} \mathrm{O}_{3}$ whisker located in parallel orientation;

3) The high volume fraction reinforced hybrid clustering region is found to be highly vulnerable to initiate crack in the cast hybrid MMC during low cycle fatigue.

\section{Acknowledgements}

The authors express gratitude to the Ministry of Education, Science, Sports and Culture of the Government of Japan for providing financial support during this research work.

\section{REFERENCES}

[1] S. Suresh, A. Mortensen and A. Needleman, "Fundamentals of Metal Matrix Composites," Butterworh/Heinemann, London, 1993.
[2] J. Hemanth, "Quartz $\left(\mathrm{SiO}_{2 \mathrm{p}}\right)$ Reinforced Chilled Metal Matrix Composite (CMMC) for Automotive Applications," Materials and Design, Vol. 30, No. 2, 2009, pp. 323-329. http://dx.doi.org/10.1016/j.matdes.2008.04.064

[3] D. B. Miracle, "Metal Matrix Composite-From Science to Technological Significance," Composite Science and Technology, Vol. 65, No. 15, 2005, pp. 2526-2540. http://dx.doi.org/10.1016/j.compscitech.2005.05.027

[4] V. K. Lindroos and M. J. Talvitie, "Recent Advances in Metal Matrix Composites," Journal of Materials Processing Technology, Vol. 53, No. 1, 1995, pp. 273-284. http://dx.doi.org/10.1016/0924-0136(95)01985-N

[5] S. Basavarajappa, G. Chandramohan and D. J. Paulo, “Application of Taguchi Technique to Study Dry-Sliding Wear Behaviour of Metal Matrix Composites," Materials and Design, Vol. 28, No. 4, 2007, pp. 1393-1398. http://dx.doi.org/10.1016/j.matdes.2006.01.006

[6] N. Chawla, C. Andres, J. W. Jones and J. E. Allison, "Effect of SiC Volume Fraction and Particle Size on the Fatigue Resistance of a $2080 \mathrm{Al} / \mathrm{SiCp}$ Composite," Metallurgical Materials Transactions A, Vol. 29, No. 11, 1998, pp. 2843-2854.

[7] A. Ayyar, G. A. Crawford, J. J. Williams and N. Chawla, "Numerical Simulation of the Effect of Particle Spatial Distribution and Strength on Tensile Behavior of Particle Reinforced Composites," Computational Materials Science, Vol. 44, No. 2, 2008, pp. 496-506. http://dx.doi.org/10.1016/j.commatsci.2008.04.009

[8] J. E. Spowart, B. Maruyama and D. Miracle, "Multi-Scale Characterization of Spatially Heterogeneous Systems: Implications for Discontinuously Reinforced Metal Matrix Composite Microstructures," Materials Science and Engineering A, Vol. 307, No. 1, 2001, pp. 51-66. http://dx.doi.org/10.1016/S0921-5093(00)01962-6

[9] S. F. Corbin and D. S. Wilkinson, "The Influence of Particle Distribution on the Mechanical Response of Particulate Metal Matrix Composite," Acta Metallurgica et Materialia, Vol. 42, No. 4, 1994, pp. 1311-1318. http://dx.doi.org/10.1016/0956-7151(94)90147-3

[10] D. L. McDanels, "Analysis of Stress-Strain, Fracture and Ductility of Aluminium Matrix Composites Containing Discontinuous Silicon Carbide Reinforcement," Metallurgical Transaction A, Vol. 16, No. 6, 1985, pp. 11051115.

[11] X. Q. Xu and D. F. Watt, "A Numerical Analysis of the Effects of Reinforcement Content on Strength and Ductility in Al(SiC)p MMCs," Acta Materialia, Vol. 44, No. 11, 1996, pp. 4501-4511. http://dx.doi.org/10.1016/1359-6454(96)00063-8

[12] D. L. Davidson, "The Effect of Particulate SiC on Fatigue Crack Growth in a Cast Extruded Aluminum Alloy Composite," Metallurgical Transcations A, Vol. 22, No. 1, 1991, pp. 97-112.

[13] J. D. Boyd, R. D. Evans, G. Klein and S. Tao, "Damage Accumulation and Fracture in Metal Matrix Composites," Proceedings International Conference on Composite Materials, Gold Coast, 14-18 July 1997, pp. 409-417.

[14] N. Bourgeois, K. Derrien and D. Baptiste, "Observation 
and Modeling of Damage Evolution in Particulate Reinforced MMC," Proceedings International Conference on Composite Materials, Whistler, 14-18 August 1995, pp. 241-248.

[15] P. B. Prangnell, S. J. Barnes, S. M. Roberts and P. J. Withers, "The Effect of Clustering on Damage Formation in Particulate Reinforced MMCs Deformed in Compression," Key Engineering Materials, Vol. 47, 1996, pp. 937-944.

[16] A. M. Murphy and T. W. Clyne, "The Effect of Initial Porosity and Particle Clustering on the Tensile Failure of Cast Particulate MMC," Proceedings International Conference on Composite Materials, Whistler, 14-18 August 1995, pp. 35-42.

[17] H. N. Yoshimura, M. Goncalves and H. Goldenstein, "The Effect of SiCp Clusters and Porosity on the Mechanical Properties of PM Al Matrix Composites," Key Engineering Materials, Vol. 127-131, 1996, pp. 985-992. http://dx.doi.org/10.4028/www.scientific.net/KEM.127-1 $\underline{31.985}$

[18] M. Li, S. Ghosh and O, Richmond, "An ExperimentalComputational Approach to the Investigation of Damage Evolution in Discontinuously Reinforced Aluminium Matrix Composite," Acta Materialia, Vol. 47, No. 12, 1999, pp. 3515-3532. http://dx.doi.org/10.1016/S1359-6454(99)00148-2

[19] T. C. Tszeng, "The Effect of Particle Clustering on the Mechanical Behaviour of Particle Reinforced Composites," Composites Part B, Vol. 29, No. 3, 1998, pp. 299308. http://dx.doi.org/10.1016/S1359-8368(97)00031-0

[20] W. X. Zhang, L. X. Li and T. J. Wang, "Interphase Effect on the Strengthening Behaviour of Particle-Reinforced Metal Matrix Composites," Computational Materials Science, Vol. 41, No. 2, 2007, pp. 145-155. http://dx.doi.org/10.1016/j.commatsci.2007.03.011

[21] Y. W. Yan, L. Geng and A. B. Li, "Experimental and Numerical Studies of the Effect of Particle Size on the Deformation Behavior of the Metal Matrix Composites," Materials Science and Engineering A, Vol. 448, No. 1, 2007, pp. 315-325.

http://dx.doi.org/10.1016/j.msea.2006.10.158
[22] D. F. Watt, X. Q. Xu and D. J. Llyod, "Effect of Particle Morphology and Spacing on the Strain Fields in a Plastically Deforming Matrix," Acta Materialia, Vol. 44, No. 2, 1996, pp. 789-799.

http://dx.doi.org/10.1016/1359-6454(95)00209-X

[23] X. Q. Xu and D. F. Watt, "A Finite Element Analysis of Plastic Relaxation and Plastic Accumulation at Second Phase Particles," Acta Materialia, Vol. 44, No. 2, 1996, pp. 801-811. http://dx.doi.org/10.1016/1359-6454(95)00210-3

[24] P. Zhang and F. Li, "Effects of Particle Clustering on the Flow Behaviour of SiC Particle Reinforced Al Metal Matrix Composites," Rare Metal Materials and Engineering, Vol. 39, No. 9, 2010, pp. 1525-1531. http://dx.doi.org/10.1016/S1875-5372(10)60123-3

[25] Md. Rafiquzzaman and Y. Arai, "Fracture Mechanism of Aluminium Cast Alloy Locally Reinforced by SiC Particles and $\mathrm{Al}_{2} \mathrm{O}_{3}$ Whiskers under Monotonic and Cyclic Load," Journal of Materials Science and Technology, Vol. 24, No. 3, 2008, pp. 273-280. http://dx.doi.org/10.1179/174328407X239028

[26] A. A. Iqbal, Y. Arai and W. Araki, "Effect of Hybrid Reinforcement on Crack Initiation and Early Propagation Mechanisms in Cast Metal Matrix Composites during Low Cycle Fatigue," Materials and Design, Vol. 45, 2013, pp. 241-252.

http://dx.doi.org/10.1016/j.matdes.2012.09.002

[27] “Aluminium Alloy Castings," JIS H5202, Japan Industrial Standard, 2002. (In Japanese)

[28] E. Y. Chen, L. Lawson and M. Meshii, "The Effect of Fatigue Microcracks on Rapid Catastrophic Failure in Al-SiC Composites," Materials Science and Engineering A, Vol. 200, No. 1, 1995, pp. 192-206. http://dx.doi.org/10.1016/0921-5093(95)07009-5

[29] Z. Z. Chen and K. Tokaji, "Effects of Particle Size on Fatigue Crack Initiation and Small Crack Growth in SiCParticulate Reinforced Aluminium Matrix Composites," Materials Letters, Vol. 58, No. 17, 2004, pp. 2314-2321. http://dx.doi.org/10.1016/i.matlet.2004.02.034

[30] ABAQUS 6.9, Dassault Systems, 2009. (Software) 